\title{
The esterification of fatty acids by Staphylococcus aureus fatty acid modifying enzyme (FAME) and its inhibition by glycerides
}

\author{
F. A. KAPRAL, S. SMITH* and D. LAL $\dagger$
}

Department of Medical Microbiology and Immunology, The Ohio State University, Columbus, $\mathrm{OH} 43210, \mathrm{USA}$

\begin{abstract}
Summary. Fifty-five randomly selected Staphylococcus aureus strains were examined for fatty acid modifying enzyme (FAME) production. Of these, $20.4 \%$ did not elaborate the enzyme. Amongst the remaining strains, the lowest level produced in culture was 0.1 unit $/ 10^{9} \mathrm{cocci}$ and the maximum was $2.01 \mathrm{U} / 10^{9}$ cocci; the median level was $0.4 \mathrm{U} / 10^{9}$ cocci. In a series of straight-chain saturated fatty acids with 11-24 carbons, all could be esterified by FAME. However, those with 15-19 carbons were generally better substrates than the others. For a particular chain length, the unsaturated forms were better substrates than the saturated form. Triglycerides with unsaturated fatty acid side chains were potent inhibitors of FAME. Diglycerides were almost as active as triglycerides, but monoglycerides were much less inhibitory. FAME was purified by gel filtration followed by hydrophobic interaction chromatography on hexyl agarose. FAME and lipase may have a role in determining the survival of $S$. aureus in lesions.
\end{abstract}

\section{Introduction}

Previous studies have shown that the elimination of Staphylococcus aureus within abscesses is mediated by the production of two kinds of bactericidal lipids. One consists of a pool of long-chain unsaturated free fatty acids and the other is an unidentified lipid with distinctive properties. ${ }^{1-3}$ When abscess homogenates are incubated with $S$. aureus culture filtrates, the amount of bactericidal activity is increased. ${ }^{1,2}$ This results from the release of more free fatty acids through the action of staphylococcal lipase on triglycerides that are also present in the lesions. ${ }^{4}$

S. aureus culture filtrates may also contain another enzyme, the fatty acid modifying enzyme (FAME), that can inactivate both kinds of bactericidal lipids. ${ }^{5}$ Inactivation of the fatty acids is accomplished by esterifying them to certain alcohols, but the mechanism for inactivating the unidentified lipid is presently unknown. Toward this end, FAME can utilise certain primary alcohols, but its preferred substrate is cholesterol. The primary purpose of this study was to determine whether FAME was also selective for the fatty acid components in the esterification reaction.

\section{Materials and methods}

\section{Staphylococcal strains}

S. aureus $18 \mathrm{Z}$, described previously, ${ }^{1,2}$ was used for

Received 16 May 1991 ; revised version accepted 23 Dec. 1991.

* Present address: Analytical Toxicology, Veterinary Administration, The Ohio State University, Columbus, OH 43210, USA.

$\dagger$ Present address: Department of Pathology, Mt Sinai Medical Center, New York, NY 10029, USA.
FAME production. Fifty-five other strains selected from our culture collection were evaluated for FAME production.

\section{FAME assay}

The enzyme was assayed as described previously ${ }^{5}$ except that 1-butanol was substituted for the ethanol. Briefly, serial three-fold dilutions of FAME in phosphate buffer $(\mathrm{pH} 6.0)$ were added to 1-butanol and radiolabelled oleic acid. After incubation, the lipids were extracted from the mixture and separated by chromatography on silica gel $\mathrm{G}$ plates. The fatty acid ester and free fatty acid spots were recovered by scraping and the amount of radioactivity incorporated was counted in a scintillation counter. The percentage of oleic acid esterified in the test conditions was calculated.

When comparing the efficacy of various fatty acids, equimolar amounts of the fatty acid being studied were substituted for the oleic acid in the reaction mixture. All other reactants and conditions were held constant.

In cases where the inhibitory effects of glycerides were studied, the glyceride and oleic acid were first dissolved in hexane and the solvent was evaporated at $37^{\circ} \mathrm{C}$. After adding buffer and butanol, the lipids were suspended by sonication and FAME was added.

\section{Chemicals}

Non-radiolabelled lipids were obtained from Matreya, Inc. (Pleasant Gap, PA, USA) and Sigma Chemical Co. (St Louis, MO, USA). 


\section{Purification of FAME}

S. aureus $18 \mathrm{Z}$ was grown in trypticase soy broth for $24 \mathrm{~h}$ and the culture supernate was concentrated to one-tenth its volume by ultrafiltration on an Amicon PM-30 membrane, then dialysed against water and lyophilised.

The preparation was further purified by gel filtration on Ultragel AcA44 and the active fractions were pooled and lyophilised. Samples were subsequently subjected to hydrophobic interaction chromatography with hexyl agarose equilibrated in $4 \mathrm{M} \mathrm{NaCl}$. After addition of the sample in $4 \mathrm{M} \mathrm{NaCl}$, the column was washed with the same diluent and.FAME was eluted with a $2-0 \mathrm{M} \mathrm{NaCl}$ gradient. The active fractions were pooled, dialysed against water, and lyophilised.

\section{Results}

\section{Production of FAME by S. aureus strains}

The production of FAME by a limited number of $S$. aureus strains was measured previously, ${ }^{5}$ but to better understand the incidence of FAME-producing strains, we examined 55 additional randomly selected strains from our culture collection. Of these, $20.4 \%$ did not produce the enzyme. From among the FAMEproducing strains, the minimum amount produced was $0.1 \mathrm{U} / 10^{9}$ cocci, the median was $0.4 \mathrm{U} / 10^{9}$ cocci, and the maximum $2.01 \mathrm{U} / 10^{9}$ cocci.

\section{Esterification of different fatty acids}

By substituting equimolar amounts of different fatty acids for the oleic acid in the reaction mixture, the relative efficacy of the fatty acids for esterification could be evaluated. When FAME was tested against a series of saturated fatty acids with chain lengths of 11-24 carbon atoms, all were esterified (table I). However, fatty acids with 15-19 carbon atoms were more effectively esterified than those with shorter or longer chain lengths. Furthermore, the enzyme had a slight preference for fatty acids with an odd number of carbon atoms over those adjacent in the series with an even number of carbon atoms. For a particular chain length, FAME esterified the unsaturated more efficiently than the saturated fatty acids (table II).

\section{Inhibition of FAME by glycerides}

In these studies, it was found that FAME was inhibited by certain triglycerides. Accordingly, a study was done to compare the efficacy of triglycerides with different fatty acid moieties for their ability to inhibit the enzyme. By mixing various amounts of triglyceride with a fixed amount of oleic acid and enzyme, and incubating the mixture under constant conditions, the molar ratio of triglyceride: oleic acid that resulted in a $50 \%$ inhibition of FAME activity could be determined (table III). In this case, the smaller the ratio, the more efficacious the triglyceride in inhibiting the enzyme. It was evident that triglycerides containing unsaturated fatty acids in the molecule were more inhibitory than triglycerides with saturated fatty acid residues. There was no obvious relationship between inhibitory capacity and the length of the side chains.

In a similar study, certain triglycerides, diglycerides and monoglycerides were compared for their ability to inhibit FAME (table IV). Whereas the diglycerides were only slightly less effective than the corresponding triglycerides, the monoglycerides were much less inhibitory.

Table I. Relative efficacy of saturated fatty acids with different chain length in esterification to 1-butanol by FAME

\begin{tabular}{cc}
\hline Fatty acid & Percentage esterification (SE) \\
\hline $11: 0$ & $19 \cdot 3(3 \cdot 1)$ \\
$12: 0$ & $22 \cdot 3(6 \cdot 2)$ \\
$13: 0$ & $38 \cdot 8(3 \cdot 2)$ \\
$14: 0$ & $25 \cdot 8(2 \cdot 4)$ \\
$15: 0$ & $49 \cdot 5(5 \cdot 4)$ \\
$16: 0$ & $37 \cdot 8(0 \cdot 98)$ \\
$17: 0$ & $55 \cdot 3(2 \cdot 9)$ \\
$18: 0$ & $33 \cdot 8(4 \cdot 3)$ \\
$19: 0$ & $37 \cdot 2(4 \cdot 6)$ \\
$20: 0$ & $18 \cdot 6(2 \cdot 2)$ \\
$21: 0$ & $34 \cdot 8(6 \cdot 5)$ \\
$22: 0$ & $15 \cdot 0(3 \cdot 7)$ \\
$23: 0$ & $28 \cdot 2(4 \cdot 2)$ \\
$24: 0$ & $17 \cdot 5(3 \cdot 4)$
\end{tabular}

Test conditions: 1 unit FAME, $0.6 \mu \mathrm{mol} 1$-butanol, $0.7 \mu \mathrm{mol}$ fatty acid; $\mathrm{pH} 6.0,37^{\circ} \mathrm{C}, 20 \mathrm{~min}$.

Table II. Relative efficacy of fatty acids differing in degree of unsaturation in esterification to 1-butanol by FAME

\begin{tabular}{lc}
\hline Fatty acid & Percentage esterification (SE) \\
\hline $16: 0$ & $37 \cdot 8(0 \cdot 98)$ \\
$16: 1$ & $44 \cdot 0(0 \cdot 73)$ \\
$18: 0$ & $33 \cdot 8(4 \cdot 3)$ \\
$18: 1$ & $45 \cdot 6(1 \cdot 3)$ \\
$18: 2$ & $50 \cdot 3(5 \cdot 2)$ \\
$18: 3$ & $49 \cdot 7(3 \cdot 5)$ \\
$18: 3$ gamma & $44 \cdot 3(0 \cdot 92)$ \\
\hline
\end{tabular}

Test conditions: 1 unit FAME, $0.6 \mu \mathrm{mol} \mathrm{1-butanol,} 0.7 \mu \mathrm{mol}$ fatty acid; pH $6.0,37^{\circ} \mathrm{C}, 20 \mathrm{~min}$.

Table III. Inhibition of FAME by triglycerides

\begin{tabular}{|c|c|c|c|c|}
\hline \multirow{2}{*}{ Triglyceride } & \multicolumn{3}{|c|}{ Side chain } & \multirow{2}{*}{$\begin{array}{l}\text { Triglyceride: } \\
\text { oleic acid } \\
\text { ratio* }\end{array}$} \\
\hline & Fatty acid & Geometry & $\Delta$ & \\
\hline Trimyristolein & $14: 1$ & cis & 9 & $1 \cdot 17$ \\
\hline Tripalmitolein & $16: 1$ & cis & 9 & 0.85 \\
\hline Triolein & $18: 1$ & cis & 9 & 1.2 \\
\hline Trilinolein & $18: 2$ & cis & 9,12 & 0.65 \\
\hline Trilinolenin & $18: 3$ & cis & $9,12,15$ & 1.4 \\
\hline Trimyristin & $14: 0$ & $\ldots$ & $\ldots$ & $7 \cdot 0$ \\
\hline Tripalmitin & $16: 0$ & $\ldots$ & $\ldots$ & $2 \cdot 6$ \\
\hline Tristearin & 18:0 & $\ldots$ & $\ldots$ & 3.5 \\
\hline Triarachidin & $20: 0$ & $\ldots$ & $\ldots$ & $4 \cdot 4$ \\
\hline
\end{tabular}

*Molar ratio of triglyceride: oleic acid to achieve $50 \%$ inhibition. 
Table IV. Inhibition of FAME by glycerides

\begin{tabular}{ll}
\hline Glyceride & Glyceride:oleic acid ratio* \\
\hline Triolein & $1 \cdot 2$ \\
1,2 Diolein & $1 \cdot 4$ \\
1,3 Diolein & $1 \cdot 4$ \\
1 Mono-olein & $2 \cdot 3$ \\
Trilinolein & $0 \cdot 65$ \\
Dilinolein & $1 \cdot 7$ \\
Monolinolein & $3 \cdot 0$
\end{tabular}

${ }^{*}$ Molar ratio of glyceride: oleic acid to achieve $50 \%$ inhibition.

Table V. Purification of $S$. aureus FAME

\begin{tabular}{lcc}
\hline Preparation & $\begin{array}{c}\text { Specific activity } \\
(\mathrm{U} / \mathrm{mg})\end{array}$ & $\begin{array}{c}\text { Recovery } \\
(\%)\end{array}$ \\
\hline $\begin{array}{l}\text { After ultrafiltration } \\
\text { After passage through } \\
\begin{array}{c}\text { Ultragel AcA44 } \\
\text { After elution from } \\
\text { hexyl agarose }\end{array}\end{array} 2^{2 \cdot 8}$ & $\begin{array}{r}100 \\
68\end{array}$ \\
\hline
\end{tabular}

\section{Purification of FAME}

Although several approaches were explored, the procedure previously described was finally selected. This usually resulted in about a 200 -fold purification with a $25-60 \%$ recovery of the enzyme (table V). Polyacrylamide gels of the final product when stained with Coomassie Blue showed a single band, but when overloaded revealed three other faint bands. SDSPAGE done on samples heated with mercaptoethanol indicated no subunit structure, but the activity of the enzyme was irreversibly destroyed.

\section{Discussion}

It was shown previously that FAME can utilise various alcohols in the esterification reaction. ${ }^{5}$ In the series of primary alcohols from methanol to 1-butanol, the greater the number of carbons in the structure, the more easily the alcohol was esterified to the fatty acid. However, cholesterol was an even better substrate, and

\section{References}

1. Dye ES, Kapral FA. Survival of Staphylococcus aureus in intraperitoneal abscesses. J Med Microbiol 1981; 14: 185-194.

2. Dye ES, Kapral FA. Partial characterization of a bactericidal system in staphylococcal abscesses. Infect Immun 1980; 30 : 198-203.

3. Dye ES, Kapral FA. Characterization of a bactericidal lipid developing within staphylococcal abscesses. Infect Immun $1981 ; 32$ : 98-104.

4. Shryock TR, Kapral FA. The production of bactericidal fatty was the only suitable alcohol found in the core of abscesses.

FAME was capable of esterifying all straightchain saturated fatty acids with 11-24 carbon atoms, although, generally, those in mid-range (C15-C19) were esterified more effectively than those at either extreme (table I). In the two series examined, C16 and $\mathrm{C} 18$, the unsaturated fatty acids were more readily esterified than were their saturated counterparts (table II). This group of fatty acids comprises the bulk of the bactericidal pool within abscesses. ${ }^{4}$ In view of this preference for long-chain unsaturated fatty acids and cholesterol, together with its temperature and $\mathrm{pH}$ optima, ${ }^{5}$ FAME appears ideally suited not only to function within abscesses, but also to assist in the organism's survival. In keeping with this premise is the observation that only FAME-producing $S$. aureus strains are able to survive or multiply within host tissues. ${ }^{5}$

The observation that triglycerides with unsaturated fatty acid moieties are potent inhibitors of FAME (table III) suggests a role for these lipids in the staphylococcal host-parasite interaction. Substantial amounts of unsaturated triglycerides are produced in abscesses $^{3,4}$ and this may represent a host response designed to keep FAME non-functional. This, in turn, suggests a new role for the staphylococcal lipase. This enzyme, produced by almost all $S$. aureus strains, may serve to counteract the efforts of the host by degrading the triglycerides. If the host can maintain an adequate supply of triglycerides within the lesion, FAME remains inactive and the bactericidal lipids are free to act on the organism. If the influx of triglycerides is limited, the lipase can reduce levels to a point where FAME can inactivate the bactericidal lipids and the staphylococci are protected.

It should be noted that, whereas conditions within abscesses are ideal for FAME activity, this is not the case for lipase. At $\mathrm{pH} \mathrm{6}$, lipase activity is only c. $5 \%$ that of the enzyme at its optimum of $\mathrm{pH} 8{ }^{5,6}$ Furthermore, the lipase is less active against the longchain triglycerides produced in abscesses than it is against triglycerides with shorter side chains in the molecule.

This investigation was supported by Public Health Service Grant AI-19879 from the National Institute of Allergy and Infectious Disease.

acids from glycerides in staphylococcal abscesses. $J \mathrm{Med}$ Microbiol 1992; 36: 288-292.

5. Mortensen JE, Shryock TR, Kapral FA. Modification of bactericidal fatty acids by an enzyme of Staphylococcus aureus. J Med Microbiol 1992; 36: 293-298.

6. Tyski S, Hryniewicz W, Jeljaszewicz J. Purification and some properties of the staphylococcal extracellular lipase. Biochim Biophys Acta 1983; 749: 312-317.

7. Muraoka T, Ando T, Okuda H. Purification and properties of a novel lipase from Staphylococcus aureus 226. J Biochem 1982; 92: 1933-1939. 